\title{
Dynamic variation in physicochemical properties of activated sludge floc from different WWTPs and its influence on sludge dewaterability and settleability
}

\author{
Weijun Zhang ${ }^{\mathrm{a}}$, Peng Yang ${ }^{\mathrm{a}, \mathrm{b}}$, Ping Xiao ${ }^{\mathrm{a}}$, Shiwei Xu ${ }^{\mathrm{c}, \mathrm{d}}$, Yuanyuan Liu ${ }^{\mathrm{a}}$, \\ Fei Liu ${ }^{\mathrm{c}}$, Dongsheng Wang ${ }^{\mathrm{a}, *}$ \\ a State Key Laboratory of Environmental Aquatic Chemistry, Research Center for Eco-Environmental Sciences, Chinese Academy of Sciences, \\ 18 Shuangqing Road, Beijing 100085, China \\ b School of Civil and Architecture Engineer, Northeast Dianli University, Jilin 132012, Jilin Province, China \\ c School of Water Resources and Environment, China University of Geosciences, Beijing 100083, China \\ d Beijing Drainage Group Company Limited, Beijing 100024,China
}

\section{H I G H L I G H T S}

- Dynamic change in physicochemical properties of activated sludges was investigated.

- Variation in sludge EPS properties from different WWTPs showed a similar pattern.

- Temperature had more significant influence on distribution and composition of EPS.

- Sludge dewaterability correlated well with the content of proteins in soluble EPS.

- Sludge settleability was primarily affected by floc size distribution and VSS.

\section{A R T I C L E I N F O}

\section{Article history:}

Received 25 August 2014

Received in revised form

11 November 2014

Accepted 13 November 2014

Available online 21 November 2014

\section{Keywords:}

Activated sludge

EPS

WWTPS

Settleability

Dewaterability

\section{G R A P H I C A L A B S T R A C T}

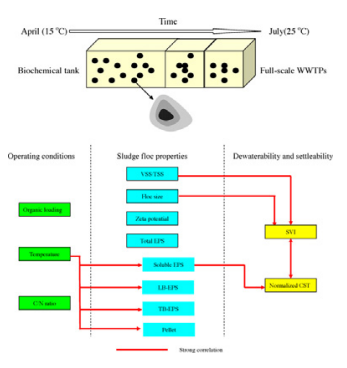

\begin{abstract}
A B S T R A C T
Biosolid-liquid separation performance plays an important role in suspended solids removal and sludge thickening and dewatering process. Since the sludge is a highly complex colloidal system, the key factors affecting sludge dewatering and settling performance were not well understood. In this study, the dynamic variation in distribution and chemical composition of extracellular polymeric substances (EPS), floc size distribution, charge property and settling and dewatering performance was investigated at four full scale WWTPs over 100 days. It was found that the change in EPS distribution and composition from different WWTPs showed a very similar pattern with operating time. The temperature rather than wastewater composition had more significant influence on content and chemical constituents of different EPS fractions. Additionally, more EPS was extracted from activated sludge at lower temperature $\left(<15^{\circ} \mathrm{C}\right)$, indicating that the binding strength of EPS with microbial cells was weak. According to Pearson's correlation analysis, sludge dewatering property correlated well with content of protein-like substances in soluble EPS, while there was a strong correlation between sludge settleability (measured by sludge volume index) and floc size and volatile suspended solid/total suspended solid ratio (VSS/TSS).
\end{abstract}

(c) 2014 Elsevier B.V. All rights reserved.

\footnotetext{
* Corresponding author. Tel.: +86 10 62849138; fax: +86 1062849138 .

E-mail address: wgds@rcees.ac.cn (D. Wang).
} 


\section{Introduction}

Wastewater treatment processes produce large quantities of sludge commonly containing over $90 \%$ water [1]. Biosolid-liquid separation by gravity settling and mechanical dewatering are of particular importance to the activated sludge process [2]. Poor settleability can cause operational problems and discharge of suspended solids to the effluent, while effective dewatering has a significant influence on sludge reduction.

Activated sludge is a heterogeneous colloid system and characterized by high specific surface area, irregular structure and negative charge [3]. Extracellular polymeric substances (EPS) are one of the most crucial constituents of activated sludge due to their specific chemical composition and structures. EPS were mainly consisted of high-molecular-weight polysaccharides (PS), proteins (PN), glycoproteins, nucleic acids, phospholipids, and humic acids (HA) [4]. EPS could act as glue and serve to bind cells together to form flocs. EPS is one of the key constituents of activated sludge and greatly affects physicochemical properties of sludge system. The EPS content and composition significantly influenced the bioflocculation ability, settleability, surface charge properties, floc size distribution and hydrophobicity and so on [4]. According to the binding strength with cells, the EPS could be fractionated into soluble EPS, loosely bound EPS (LB-EPS) and tightly bound EPS (TBEPS). The soluble EPS was mainly composed by dissolved high MW biopolymers while the bound EPS primarily contained cell capsule and loose biopolymers [5]. Li and Yang found that the sludge dewatering properties were much more strongly correlated with the concentration of LB-EPS than with the concentration of TB-EPS, and excessive LB-EPS could weaken the floc structure resulting in poor bioflocculation and sludge-water separation performance [6]. Additionally, they found that the sludge flocculating behavior, settleability, compressibility and dewaterability correlated well with LB-EPS content rather than TB-EPS content under the non-steadystate operation.

Activated sludge processes are characterized by transient operating conditions. The environmental conditions change with time on short term (h) as well as on long term scales (days, months). Many factors change simultaneously and even small changes in the floc properties can affect the performance of the sludge-water separation performance. In most previous studies, the bioflocculation, settling and dewatering properties of activated sludge have been performed either in controlled laboratory or pilot scale systems where only a limited number of parameters have been varied at the same time. Therefore, the objective of this work was to: (1) monitor the dynamic variation in EPS distribution and composition of sludge floc from three WWTPs; (2) investigate the effect of operating conditions (SRT, temperature) and influent qualities on physicochemical properties of sludge floc; and (3) get insight into the relationships between EPS properties and sludge dewatering and settling performance.

\section{Materials and methods}

\subsection{Sources of sludges}

28 wastewater sludge samples were collected from sludge recycle pumping lines of the three full-scale WWTPs (four processes) in Beijing from May to October, 2013, each mainly treating domestic wastewater. The treatment process of each WWTP was presented in Table 1.

The influent qualities and operating conditions can be found in Table 2. The collected samples were transported to a laboratory within $6 \mathrm{~h}$ after sampling and then stored at $4{ }^{\circ} \mathrm{C}$ prior to analysis. Basic properties of all wastewater sludge were given in Table 1 . The QHA and QHM received the same influent.

\subsection{Analytical methods}

\subsubsection{Basic properties}

A laser diffraction instrument (Malvern Mastersizer 2000, Malvern, UK) was used to measure dynamic floc size. $\mathrm{pH}$ was measured by $\mathrm{pH}$ meter (pHS-3C, Shanghai, China). Zeta potential was determined with Malvern Zetasizer 2000. Other sludge parameters, including total suspended solid (TSS) and volatile suspended solids (VSS), were analyzed following standard methods. TOC (total organic carbon) was determined with a TOC analyzer (Teledyne Tekmar, USA).

\subsubsection{Determination of sludge dewaterability and settleability}

Sludge dewaterability was measured with a portable capillary suction time (CST) instrument (CST 304B, Triton, UK) equipped with an $18 \mathrm{~mm}$ diameter funnel and Whatman no. 17 chromatographygrade paper. The CST values were normalized by dividing them by the initial TSS concentration and then expressed in units of seconds per liter per gram TSS. The sludge settleability was characterized by the sludge volume index (SVI), which is defined as the volume (in $\mathrm{mL}$ ) occupied by $1 \mathrm{~g}$ of sludge after $30 \mathrm{~min}$ of settling in a $1 \mathrm{~L}$ cylinder.

\subsubsection{Extraction and analysis of EPS}

EPS fractionation process of sludge samples was modified based on the procedures described by Yu et al. [7]. Firstly, raw sludge sample was settled down at $2000 \mathrm{~g}$ for $15 \mathrm{~min}$, and the supernatant was collected as soluble EPS. The sediment was resuspended to its initial volume with phosphate buffer solution consisting of $\mathrm{Na}_{3} \mathrm{PO}_{4}$, $\mathrm{NaH}_{2} \mathrm{PO}_{4}, \mathrm{NaCl}$ and $\mathrm{KCl}$. And then the suspension was transferred and centrifuged at $5000 \mathrm{~g}$ for $15 \mathrm{~min}$, and the supernatant and sediments were collected separately. This supernatant was used to determine LB-EPS later. The collected sediment was re-suspended with the phosphate buffer solution to the original volume following by treatment with ultrasound at $20 \mathrm{kHz}$ and $480 \mathrm{~W}$ for $10 \mathrm{~min}$. The extracted solution was centrifuged at $20,000 \times g$ for $20 \mathrm{~min}$ and separated as TB-EPS. Finally, the solid residues were again re-suspended with the buffer to the original volume. This fraction was the pellet. The particulates present in the supernatant, soluble EPS, LB-EPS, and TB-EPS solutions were removed with polytetrafluoroethylene membranes with a pore size of $0.45 \mu \mathrm{m}$ prior to chemical composition analysis. Total extractable EPS for each EPS fraction was defined as the sum of protein, carbohydrate and humic substances.

All chemical analyses were carried out in duplicate using chemicals of analytical grade. The protein, carbohydrate and humic substances in extracted EPS were determined according to procedure described by Wang et al. [8]. Polysaccharide was measured using the anthrone method with a glucose standard (Sinopharm). Protein and humic substances were determined with the Lowry procedure using bovine serum albumin (BSA) (Sigma) and humic acid (Sigma) as standards respectively. In addition, the molecular weight distribution of EPS was measured with high performance size-exclusion chromatography (HPSEC). MW was measured by a Waters liquid chromatography system which was consisted of Waters 2487 Dual $\lambda$ Absorbance Detector, Waters 1525 pump system. A Shodex KW 802.5 column (Shoko, Japan) was used for separation. The mobile phase, Milli-Q water buffered with $5 \mathrm{mM}$ phosphate to $\mathrm{pH} 6.8$, and $0.01 \mathrm{M} \mathrm{NaCl}$, was filtered through a $0.22 \mu \mathrm{m}$ membrane, and then degassed for $30 \mathrm{~min}$ by means of ultrasonication for $0.5 \mathrm{~h}$ before being used to the column. $600 \mu \mathrm{L}$ sample was injected at a flow rate of $0.8 \mathrm{~mL} \mathrm{~min}^{-1}$. Polystyrene sulfonate standards (Sigma-Aldrich, USA) of molecular weights 1.8-32 kDa were used for apparent molecular weight (AMW) calibration. 
Table 1

Process descriptions of the wastewater treatment plants.

\begin{tabular}{|c|c|c|c|c|c|}
\hline Treatment plant & Source of wastewater & Biological process & Chemical dosage & SRT $^{\text {a }}$ (days) & $\mathrm{SVI}^{\mathrm{b}}(\mathrm{mL} / \mathrm{g})$ \\
\hline QHAO & Mainly domestic & Membrane bioreactor (MBR) & - & $10-12$ & $96-197$ \\
\hline $\mathrm{QHM}$ & Mainly domestic & Anaerobic/anoxic/oxic $(\mathrm{A} / \mathrm{A} / \mathrm{O})$ & - & $20-30$ & $45-101$ \\
\hline JXQ & Mainly domestic & Oxidation ditch & Aluminum sulfate & $10-12$ & $140-308$ \\
\hline GBD & Mainly domestic & $\mathrm{A} / \mathrm{O}$ (primary settling tank) & Aluminum sulfate & $10-12$ & $87-116$ \\
\hline XHM & Mainly domestic & $\mathrm{A} / \mathrm{A} / \mathrm{O}$ (primary settling tank) & - & $10-12$ & $103-152$ \\
\hline
\end{tabular}

a Solids retention time (SRT).

b Sludge volume index (SVI); data obtained from the treatment plants.

Table 2

Influent and effluent quality of WWTP and sludge sampling date.

\begin{tabular}{|c|c|c|c|c|c|c|c|}
\hline \multirow[t]{2}{*}{ No. } & \multirow[t]{2}{*}{ Source } & \multicolumn{5}{|l|}{ Operating conditions } & \multirow[t]{2}{*}{ Sampling date } \\
\hline & & Water temperature $\left({ }^{\circ} \mathrm{C}\right)$ & $\mathrm{COD}(\mathrm{mg} / \mathrm{L})$ & $\mathrm{NH}_{4}{ }^{+}-\mathrm{N}(\mathrm{mg} / \mathrm{L})$ & $\mathrm{TP}(\mathrm{mg} / \mathrm{L})$ & $\mathrm{COD} / \mathrm{N}$ ratio & \\
\hline 1 & QHA & 20.3 & 539 & 51.2 & 6.2 & 10.5 & \multirow{4}{*}{ 2013-05-06 } \\
\hline 2 & $\mathrm{QHM}$ & 19.6 & 850 & 54.9 & 6.1 & 15.5 & \\
\hline 3 & JXQ & 19.9 & 698 & 59.8 & 5.8 & 11.7 & \\
\hline 4 & GBD & 19.6 & 440 & 39.7 & 4.3 & 11.1 & \\
\hline 5 & QHA & 21.5 & 555 & 52.2 & 7.0 & 10.6 & \multirow{4}{*}{ 2013-05-21 } \\
\hline 6 & QHM & 22.1 & 1375 & 50.0 & 10.6 & 27.5 & \\
\hline 7 & JXQ & 20.0 & 650 & 56.5 & 6.1 & 11.5 & \\
\hline 8 & GBD & 20.8 & 459 & 42.5 & 5.1 & 10.8 & \\
\hline 9 & $\mathrm{QHA}$ & 22.3 & 508 & 50.2 & 6.0 & 10.1 & \multirow{4}{*}{ 2013-06-03 } \\
\hline 10 & $\mathrm{QHM}$ & 22.8 & 837 & 50.9 & 6.8 & 16.5 & \\
\hline 11 & JXQ & 22.8 & 700 & 53.8 & 6.5 & 13.0 & \\
\hline 12 & GBD & 22.5 & 548 & 41.3 & 5.2 & 13.3 & \\
\hline 13 & QHA & 24.1 & 441 & 45.1 & 5.5 & 9.8 & \multirow{4}{*}{ 2013-06-25 } \\
\hline 14 & QHM & 24.0 & 744 & 41.6 & 6.6 & 17.9 & \\
\hline 15 & JXQ & 23.8 & 578 & 48.6 & 5.7 & 11.9 & \\
\hline 16 & GBD & 23.7 & 430 & 36.9 & 4.6 & 11.6 & \\
\hline 17 & $\mathrm{QHA}$ & 25.1 & 441 & 40.2 & 6.1 & 14.8 & \multirow{4}{*}{ 2013-07-10 } \\
\hline 18 & $\mathrm{QHM}$ & 24.5 & 744 & 42.5 & 4.7 & 10.1 & \\
\hline 19 & JXQ & 25.1 & 578 & 42.4 & 5.0 & 11.6 & \\
\hline 20 & GBD & 25.0 & 430 & 32.5 & 3.9 & 13.4 & \\
\hline 21 & $\mathrm{QHA}$ & 15.0 & 249 & 48.9 & 5.5 & 5.1 & \multirow{4}{*}{ 2013-10-15 } \\
\hline 22 & $\mathrm{QHM}$ & 15.0 & 696 & 53.4 & 5.7 & 13.0 & \\
\hline 23 & JXQ & 14.4 & 656 & 60.3 & 6.5 & 10.9 & \\
\hline 24 & GBD & 14.9 & 390 & 41.2 & 4.3 & 9.5 & \\
\hline 25 & QHA & 10.0 & 261 & 48.9 & 5.5 & 5.3 & \multirow{4}{*}{ 2013-12-12 } \\
\hline 26 & QHM & 11.0 & 586 & 41.6 & 4.7 & 13.0 & \\
\hline 27 & JXQ & 10.4 & 643 & 58.6 & 6.5 & 10.9 & \\
\hline 28 & GBD & 10.9 & 468 & 46.5 & 4.3 & 9.5 & \\
\hline
\end{tabular}

COD: chemical oxygen demand; $\mathrm{N}$ : nitrogen.

\subsection{Statistical analysis}

Correlation analysis was carried out using the software SPSS version 16.0 for Windows (SPSS). Pearson's correlation coefficient $(r)$ was used to evaluate the linear correlation between physicochemical properties and CST. This correlation ranges from -1 to +1 . A correlation of 1 , whether it is positive or negative, is a perfect correlation. A correlation of 0 denotes no relationship between two variables. In general, a correlation of $0.8-1$ (positive or negative) is regarded as a high correlation. $r$ of $0.4-0.7$ means moderate correlation. $r$ of $0.2-0.4$ regarded as low correlations. The correlations were considered statistically significant at a $95 \%$ confidence interval $(p<0.05)$.

\section{Results}

\subsection{Variation in sludge dewaterability and settleability with} operating time

The CST from various WWTPs showed different changing trends with operating time (Fig. 1(a)). JXQ exhibited the poorest sludge dewatering property while no significant variation in sludge dewaterability for other sludges. It should be noted that the CST for most of sludges reached minimum in the summer. The effectiveness of bioflocculation and settling of activated sludge is often characterized by the SVI. The lower the SVI, the denser the settled sludge and thus better the settleability of the sludge. In general, an activated sludge with a SVI below 120 is considered satisfactory while over 150 is regarded as bulking. It can be seen from Fig. 1(b) that SVI for each WWTP was relatively stable during operating time and followed the order of JXQ (bulking) $>$ QHAO $>$ QHM $>$ GBD. This result revealed that the sludge settleability was more likely to be influenced by process options of WWTPs rather than influent characteristics and environmental conditions.

\subsection{Variation in floc size and zeta potential of activated sludge}

Evaluating the frequency of the particles occurrence in different specific size classes represents a fast way to detect the floc size variability under varying conditions during the wastewater treatment [9]. Malvern Mastersizer 2000s is capable of providing rapid, reproducible results of the particle size distribution of activated sludge, with no adverse shear effect on the floc structural properties. Fig. 2(a) showed that the average floc size $\left(d_{0.5}\right)$ of all sludge 
(a)

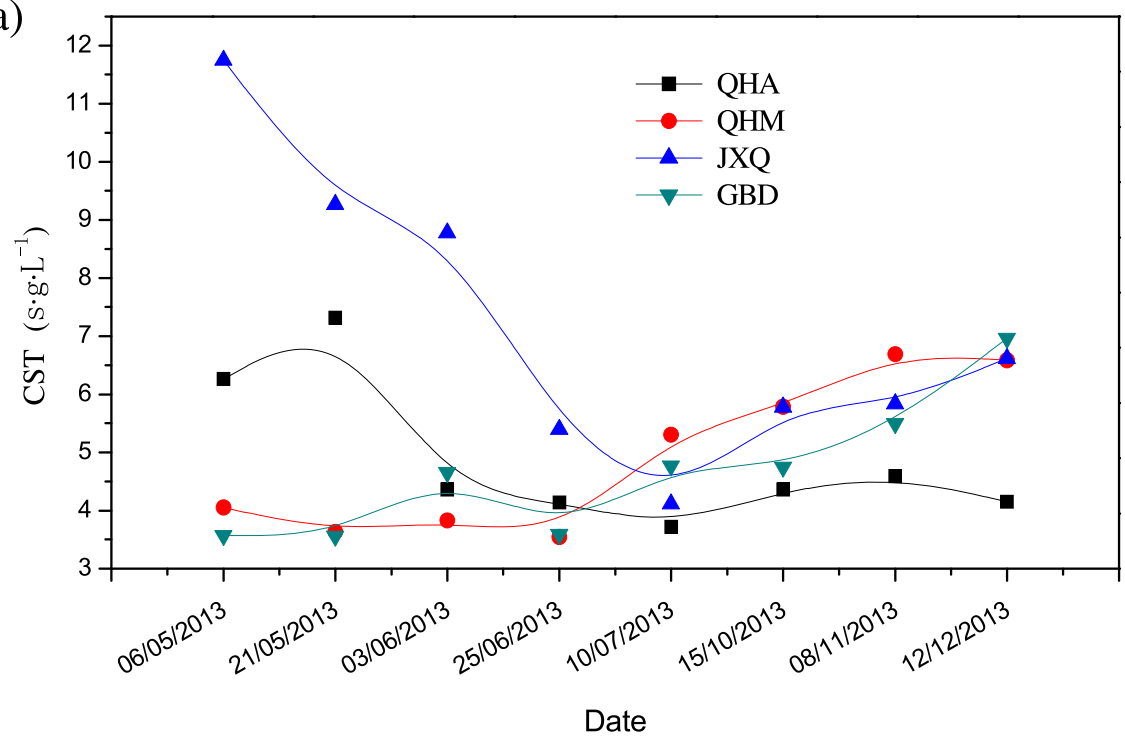

(b)

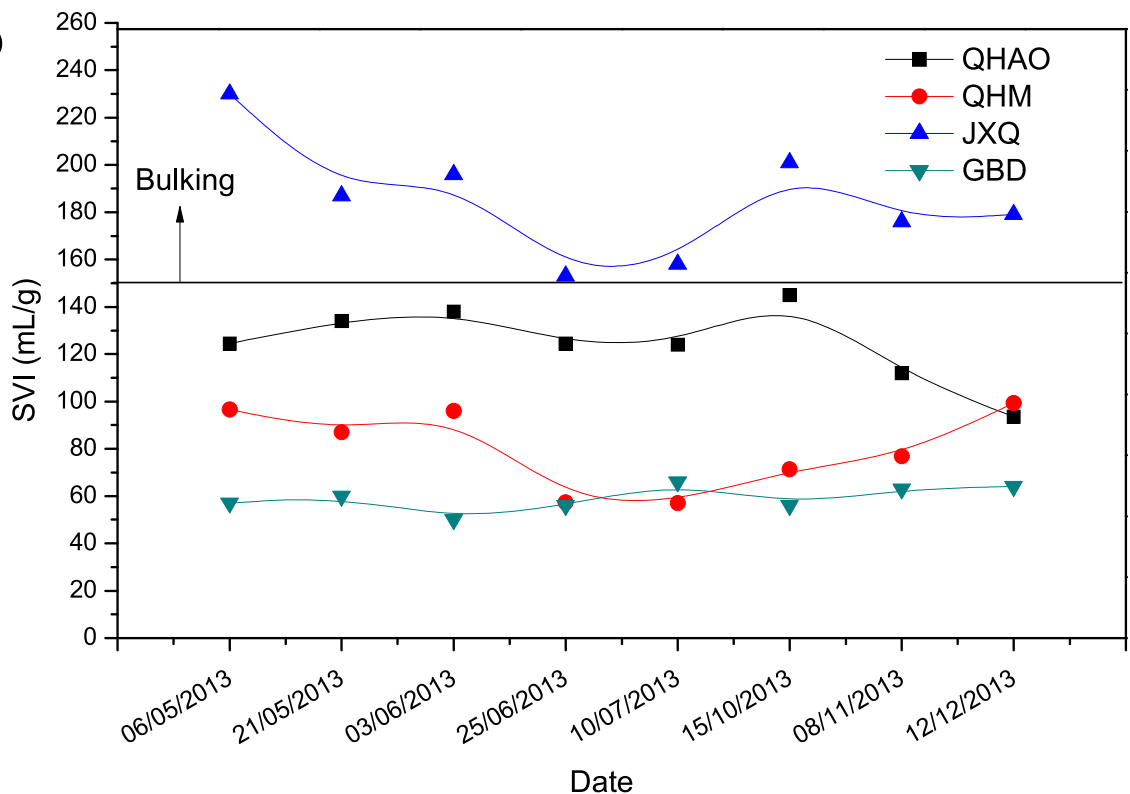

Fig. 1. Change in CST (a) and SVI (b) with operating time.

samples were in the range from $54.80 \mu \mathrm{m}$ to $126.33 \mu \mathrm{m}$, no obvious variation was observable for each WWTP with operating time. The average floc size of GBD, QHA, JXQ and QHM were $95 \mu \mathrm{m}, 83 \mu \mathrm{m}$, $62 \mu \mathrm{m}$ and $71 \mu \mathrm{m}$ respectively. As depicted in Fig. 2(b), the sludge particles carried negative charge with a zeta potential of -3.8 to $-19 \mathrm{mV}$. This is due to the ionization of the anionic functional groups, such as carboxylic and phosphate. It should be pointed out that the aluminum sulfate was dosed in influent of secondary settling tank for enhancing phosphorus removal in GBD WWTP. The trivalent cations $\left(\mathrm{Al}^{3+}, \mathrm{Fe}^{3+}\right)$ can serve to bind the negatively charged EPS and improve bioflocculation through electrical neutralization and bridging [10]. Therefore, the activated floc size in GBD WWTP was larger than that in other WWTPs.

\subsection{Distribution and composition of sludge EPS}

\subsubsection{Content of soluble EPS, LB-EPS and TB-EPS}

The variation in organic content of different EPS fraction can be found in Fig. 3. The soluble EPS was the dominant fraction of sludge EPS. The SEPS, LB-EPS and TB-EPS accounted for $53.1-72.3 \%$,
$9-17 \%$ and $15-27 \%$ of total EPS. In addition, it can be seen that maximum extractable EPS content was found at low temperatures, while at higher temperatures the content of total EPS content was significantly lower. Wilen et al. also observed that the flocs were much more open and irregularly shaped during the winter months compared to in the summer [11]. Through long-term monitoring of activated sludge floc properties, it was found that content of bound EPS reached maximum in the winter while minimum in the summer, low EPS concentration was always related to good filterability. It was because that microorganism would release more EPS under adverse operation conditions, such as low temperature and presence of toxic compounds [12].

\subsubsection{Variation in EPS composition located in different EPS fractions}

Fig. 4 showed that, for all WWTPs studied, the protein concentration in EPS fractions (soluble EPS, LB-EPS and TB-EPS) was significantly lower while that in pellet was greatly increased at higher temperatures (May-July). This observation revealed that the binding strength of protein-like compounds to microbial cells 

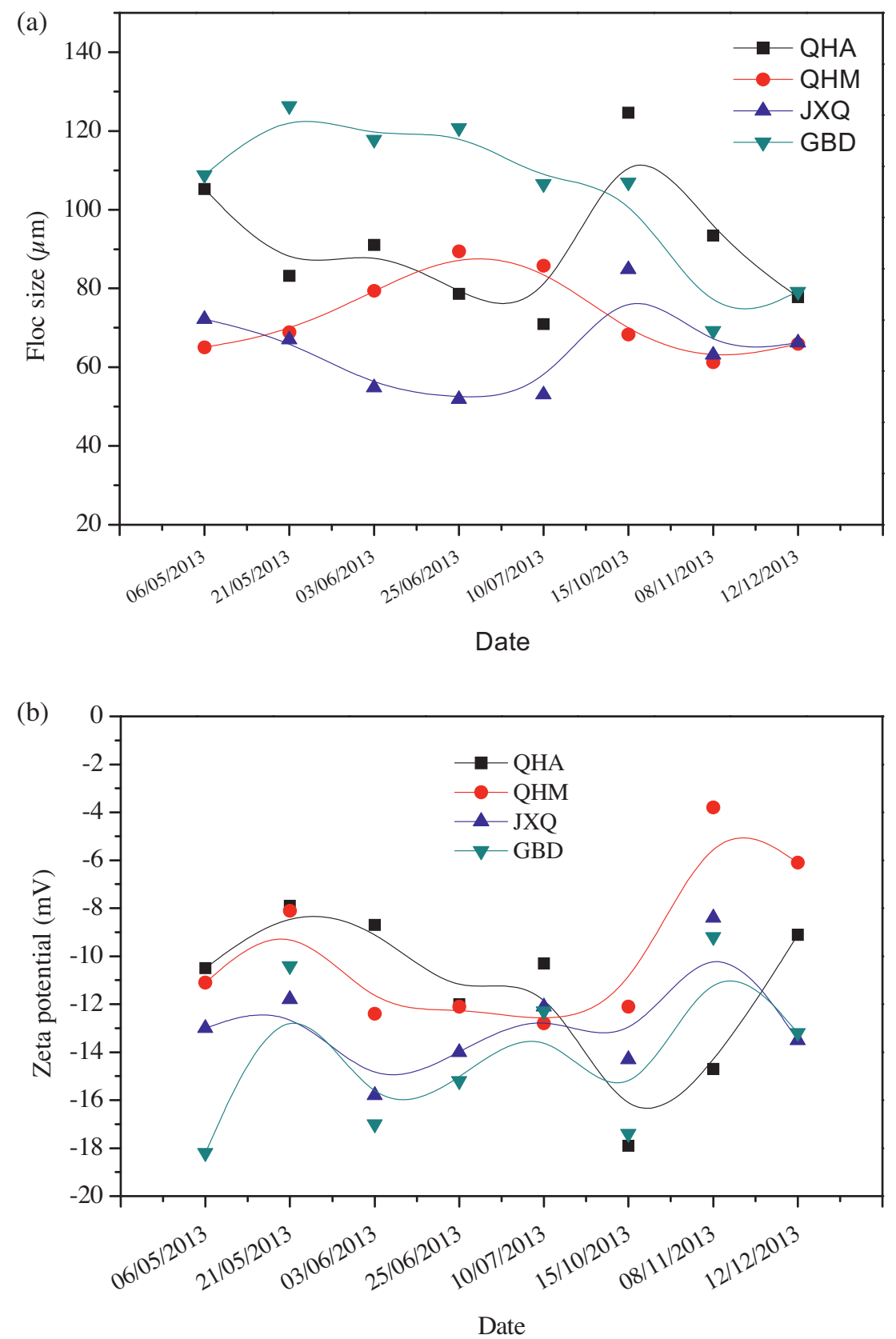

Fig. 2. Variation in floc size (a) and zeta potential (b) with operating time.

was much stronger at higher temperatures. Proteins were found to be more dominant than polysaccharides and humic in most samples. In addition, it was noted that extracellular proteins secreted by bacteria were actually enzymes, the total content of which was higher in summer, and this was corresponding to the enhancement of microbial activity.

Most microbial exopolysaccharides are highly soluble in water, and capsule-forming polysaccharides are attached to the cells surface through covalent bonds to other surface polymers [13]. Fig. 5 showed that a similar changing trend was observed for polysaccharide in EPS fractions from different WWTPs. The extractable PS in all sludge layers showed very similar pattern, it reached the minimum in summer (22 May-10 July 2004). More than $80 \%$ of PS was located in pellet. Since the polysaccharides are highly biodegradable polymers, they are very likely to be more easily degraded in the presence of high exoenzymes in summer.
It can be seen from Fig. 6 that no clear trend was observed for humic acid. Humic substances in sludge EPS primarily came from two sources: adsorption from wastewater [14] and hydrolytic conversion from other biopolymers such as proteins [15]. Since the microbial activity was enhanced at higher temperature, the increase of degradation of the organic matter in the sewer system resulted in increase of humic-like substances which were lack of biodegradability. As stated by Xi et al., the microorganisms produced more biomass associated products (BAP) mainly composed by humic substances under substrate-limited condition. BAP was primarily originated from hydrolysis of LB-EPS [15].

\subsubsection{MW analysis of different EPS fractions}

As showed in Figure S1 of supporting information, the chromatographic fingerprints were very similar for all sludge samples. Three main molar mass fractions in HPSEC chromatograms can be distinguished: macromolecular fraction ( $>4000 \mathrm{Da})$-mainly 

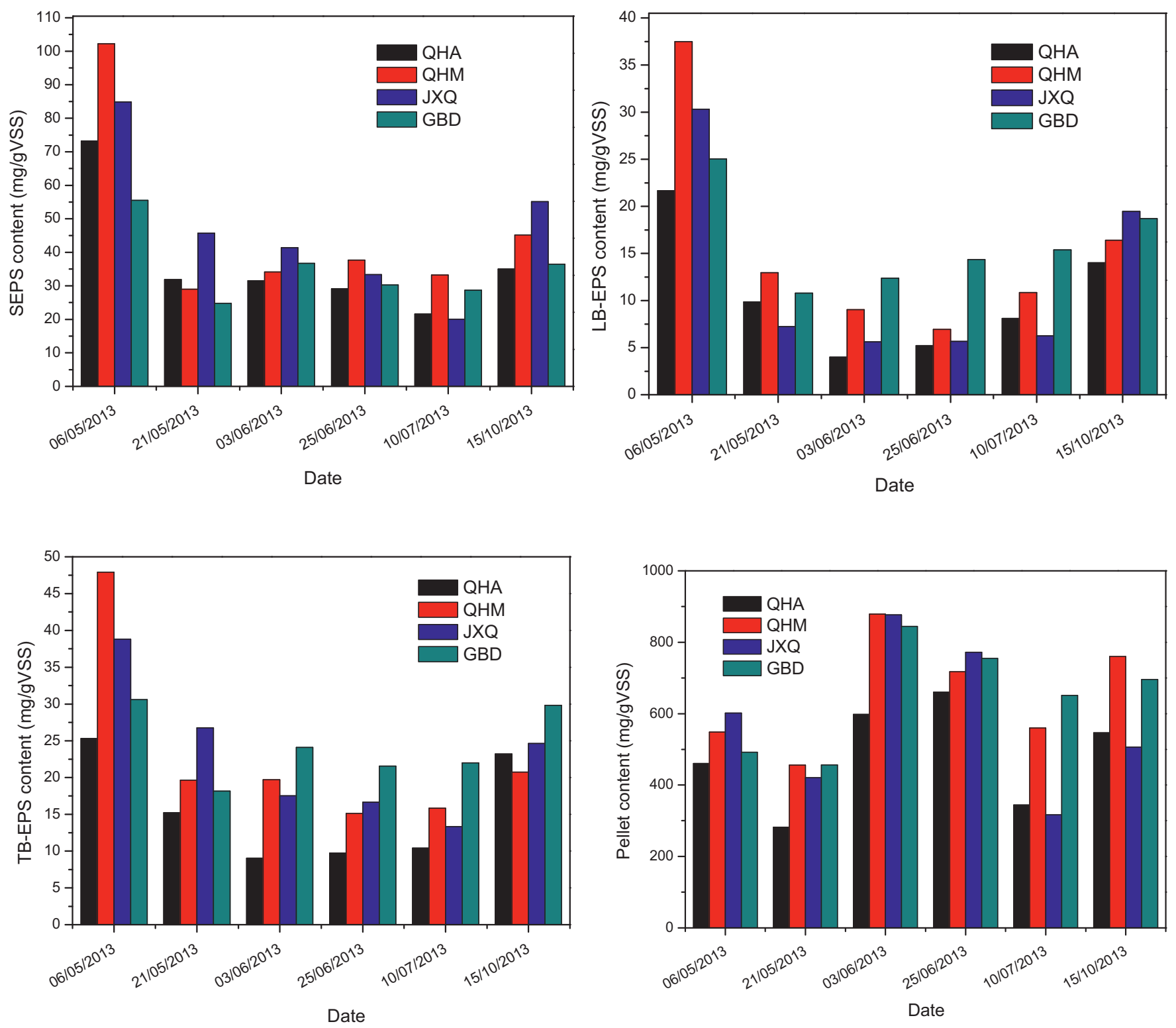

Fig. 3. Variations in extractable organic content of different EPS fractions.

consisting of carbohydrates and proteins; mid molecular fraction (1000-4000 Da)-consisting of humic substances with high aromaticity index or UV response; low molecular fraction (<1000 Da)-consisting of building blocks and organic acids. Since the HPSEC profiles of different sludge samples were very similar, chromatograms can be assumed as the typical "fingerprint of municipal full-scale WWTPs". This corresponded to the other findings [16]. In addition, it can be seen that DOMs located in different sludge layers had similar chemical composition, but the concentrations varied significantly from April to July. Soluble EPS had much higher humic acid with MW from 2000 to 6000 Da than bound EPS in the summer, while bound EPS was always mainly composed with biopolymer with high MWs. This observation was in agreement with results reported by Ramesh et al., who found that soluble EPS contained small particles (100-200 nm) of negative charges, and the bound EPS comprised two groups of particles of larger sizes (200-400 nm and 700-2000 nm) and more negative charges [17]. The soluble EPS contained mainly polysaccharides, lipids, and proteins, but the SMP had more humic substances than the soluble EPS. Furthermore, the signal response of organic matter with medium
MW was intensified from April to July, indicating an increased relative concentration ratio of humic acid in soluble EPS.

Supplementary material related to this article can be found, in the online version, at http://dx.doi.org/10.1016/j.colsurfa. 2014.11.027.

\subsection{Correlation of influent quality and operating condition and EPS properties of AS}

Table 3 showed that the temperature was negatively correlated with content of SEPS $\left(R^{2}=-0.736, p<0.01\right)$, LB-EPS $\left(R^{2}=-0.794\right.$, $p<0.01)$, TB-EPS $\left(R^{2}=-0.596, p<0.01\right)$ and pellet $\left(R^{2}=-0.793\right.$, $p<0.01)$. PS and humic content in SEPS, LB-EPS, TB-EPS and PN in SEPS were also negatively correlated to water temperature. Of the EPS components, only HA in pellet was moderately correlated with organic loading. There was no correlation between carbon/nitrogen ratios in the wastewater and EPS properties in the sludge. These results indicated that temperature have more important influence on distribution and composition of EPS in sludge floc than influent qualities. 

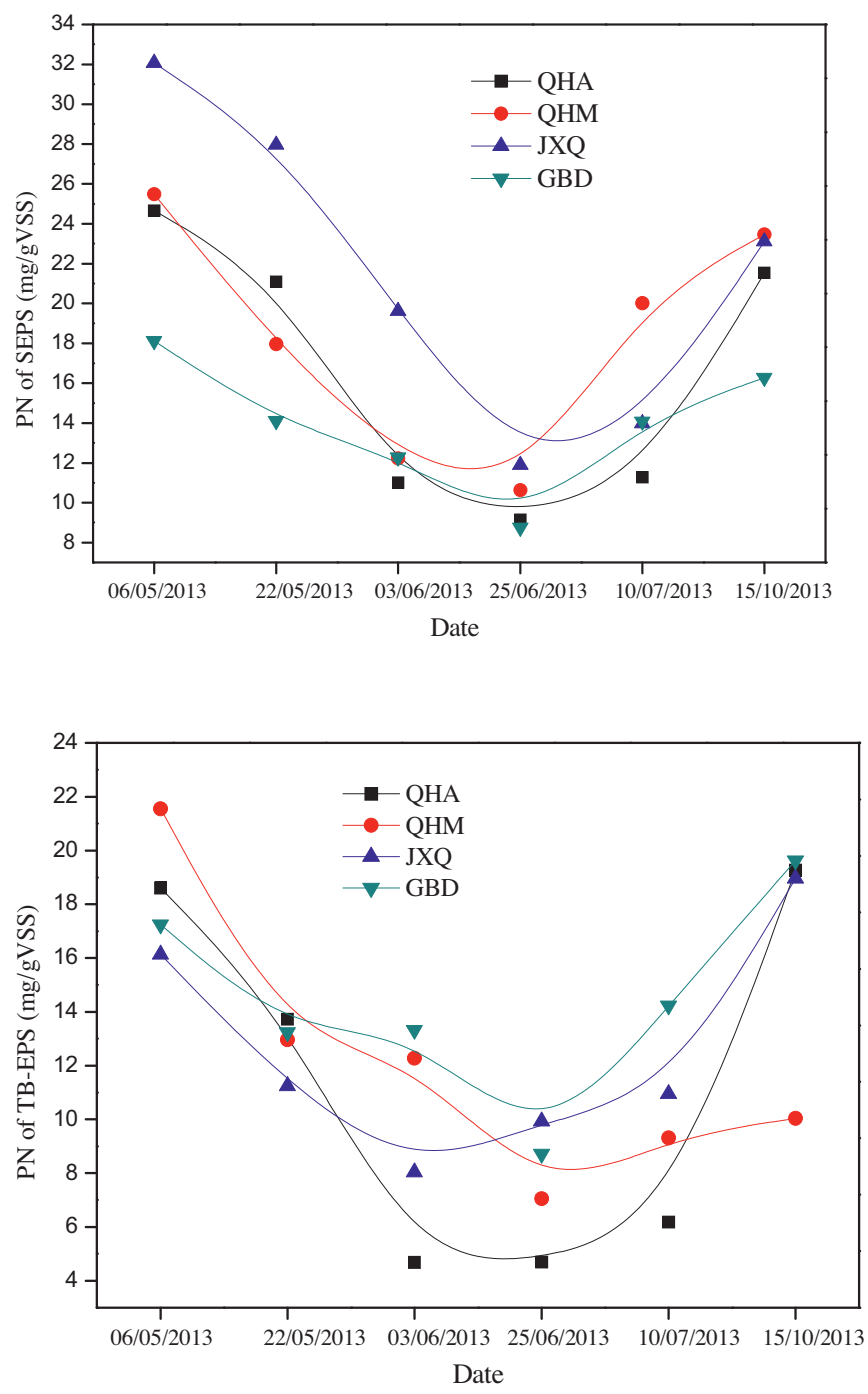
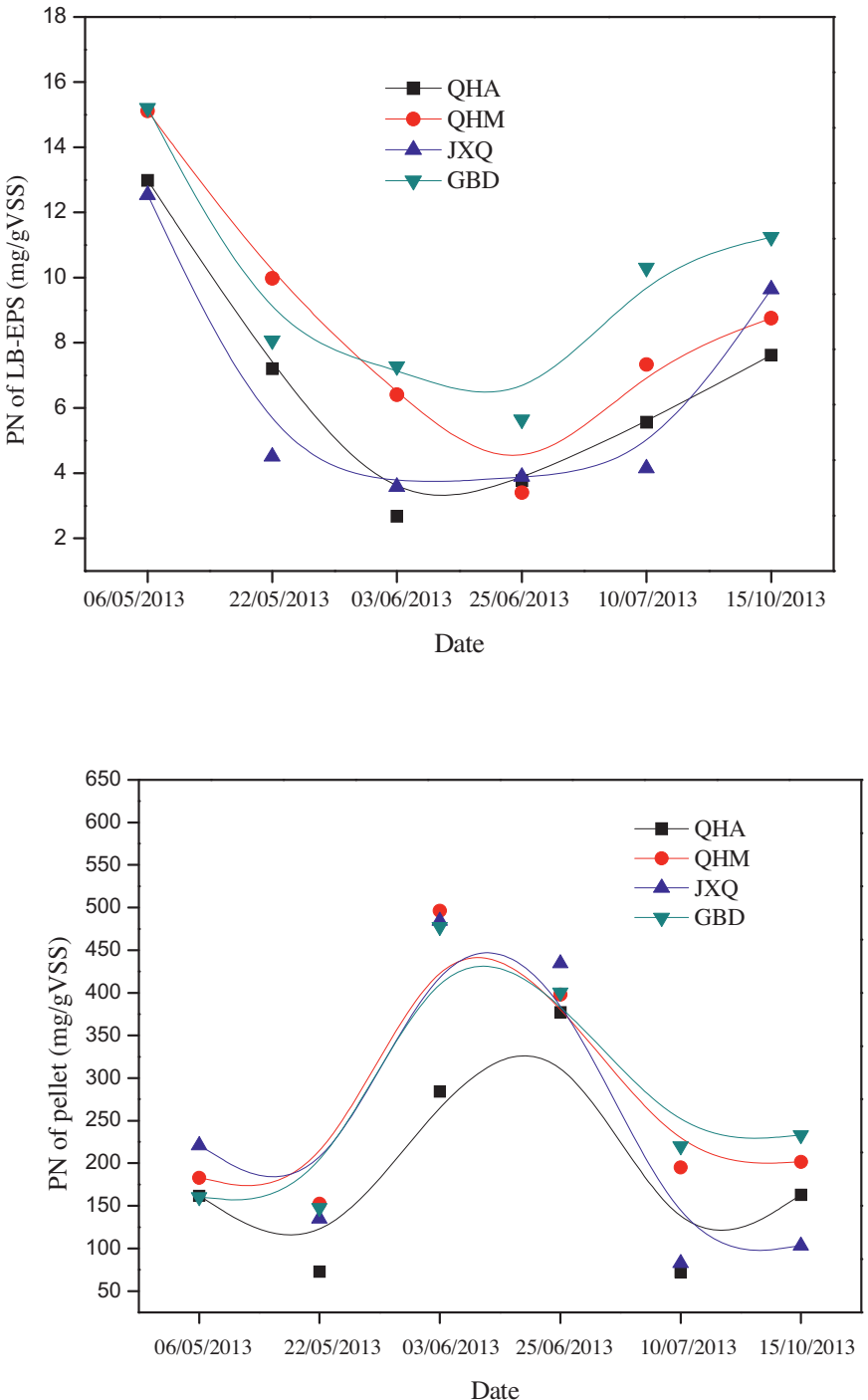

Fig. 4. Protein concentration of four EPS fractions in activated sludge from different WWTPs.

3.5. Correlation between sludge dewaterability and settleability and physicochemical properties of flocs

As shown in Table 4, a strong positive correlation was found between CST and SVI $\left(R^{2}=-0.57, p<0.01\right)$. In addition, CST correlated well with the total content of soluble EPS $\left(R^{2}=0.58, p<0.01\right)$ and PN concentration in SEPS $\left(R^{2}=0.76, p<0.01\right)$. A medium positive correlation was observed between CST and PS in total EPS fraction $\left(R^{2}=0.48, p<0.05\right)$. The $d(0.1), d(0.5)$ and $d(0.9)$ values indicate that $10 \%, 50 \%$ and $90 \%$ of the particles measured were less than or equal to the size stated, respectively. There was a negative correlation between SVI and $d_{0.1}\left(R^{2}=-0.64, p<0.01\right)$ and $d_{0.5}\left(R^{2}=-0.58, p<0.01\right)$ followed by $d_{0.9}\left(R^{2}=-0.45, p<0.05\right)$. It is generally accepted that the fine particles in sludge system are difficult to settle. Furthermore, a strong positive correlation was observed between SVI and VS/TS, indicating that a sludge with high organic fraction is more difficult to settle. No correlation was found between zeta potential and CST and SVI.

Table 3

Coefficients of correlation $\left(R^{2}\right)$ for linear regression between operating conditions and EPS properties of activated sludges $(n=20)$.

\begin{tabular}{|c|c|c|c|c|c|c|c|c|c|c|c|c|c|}
\hline \multirow[t]{2}{*}{ Operating conditions } & & \multicolumn{6}{|c|}{ Sludge fractions } & \multicolumn{4}{|l|}{ PS } & \multicolumn{2}{|l|}{ PN } \\
\hline & & SEPS & LB & TB & Pellet & SEPS & LB & TB & Pellet & SEPS & LB & TB & Pellet \\
\hline \multirow{2}{*}{ Organic loading } & Pearson correlation & -0.24 & -0.44 & -0.26 & -0.11 & -0.23 & -0.07 & -0.05 & -0.22 & -0.026 & -0.36 & -0.195 & 0.34 \\
\hline & $p$ value & 0.32 & 0.05 & 0.269 & 0.649 & 0.29 & 0.73 & 0.82 & 0.31 & 0.903 & 0.08 & 0.36 & 0.11 \\
\hline \multirow{2}{*}{ Carbon/nitrogen } & Pearson correlation & -0.32 & -0.41 & -0.27 & -0.24 & -0.30 & -0.16 & -0.07 & -0.13 & -0.074 & -0.34 & -0.245 & 0.22 \\
\hline & $p$ value & 0.13 & 0.05 & 0.21 & 0.27 & 0.12 & 0.42 & 0.721 & 0.50 & 0.707 & 0.076 & 0.208 & 0.26 \\
\hline \multirow{2}{*}{ Temperature } & Pearson correlation & $-.74^{* *}$ & $-.79^{* *}$ & $-.60^{* *}$ & $-.79^{* *}$ & -.46 & $-.51^{* *}$ & $-.47^{*}$ & 0.09 & $-.52^{* *}$ & -0.26 & -0.17 & 0.04 \\
\hline & $p$ value & 0 & 0 & 0.003 & 0 & 0.015 & 0.006 & 0.012 & 0.66 & 0.185 & 0.005 & 0.37 & 0.83 \\
\hline
\end{tabular}

SEPS: soluble EPS; LB: loosely bound EPS; TB: tightly bound EPS; OC: organic content; ZP: zeta potential; PS: polysaccharide; PN: protein.

* Correlation is significant at the 0.05 level (2-tailed).

** Correlation is significant at the 0.01 level (2-tailed).

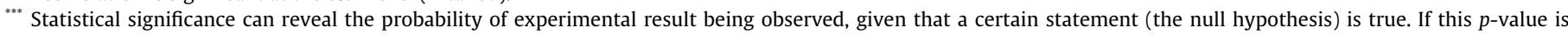
sufficiently small, the experimenter can safely assume that the null hypothesis is false. 
Table 4

Coefficients of correlation $\left(R^{2}\right)$ for linear regression between sludge dewaterability and settleability and physicochemical properties of flocs.

\begin{tabular}{|c|c|c|c|c|c|c|c|c|c|c|c|c|c|c|c|c|c|c|c|c|c|c|c|c|c|c|}
\hline & \multirow[t]{2}{*}{ SVI } & \multicolumn{6}{|c|}{ Basic properties of activated sludge } & \multicolumn{4}{|c|}{ Sludge fractions } & \multicolumn{4}{|l|}{ PS } & \multicolumn{4}{|l|}{$\mathrm{PN}$} & \multicolumn{4}{|l|}{$\mathrm{HA}$} & \multicolumn{3}{|c|}{ Total EPS } \\
\hline & & $\mathrm{ZP}$ & $d_{0.1}$ & $d_{0.5}$ & $d_{0.9}$ & $\mathrm{pH}$ & $\mathrm{VS} / \mathrm{TS}$ & SEPS & LB & TB & $\mathrm{P}$ & SEPS & LB & TB & $\mathrm{P}$ & SEPS & LB & TB & $\mathrm{P}$ & SEPS & LB & TB & $\mathrm{P}$ & PS & PN & $\mathrm{HA}$ \\
\hline CST & $.57 *$ & -.124 & -.45 & -.35 & -.189 & .061 & .24 & $.58 *$ & .349 & .031 & $.45^{*}$ & .28 & $.47^{*}$ & $.44^{*}$ & .272 & .76 & .160 & .111 & -.113 & .17 & .15 & .113 & -.12 & $.46^{*}$ & .157 & .09 \\
\hline SVI & 1 & .26 & -.64 & $-.58 *$ & $-.45^{*}$ & .114 & .60 & .160 & .125 & -.237 & .233 & -.069 & .065 & .075 & -.041 & .421 & -.224 & -.092 & -.200 & .051 & -.078 & .022 & -.227 & .071 & -.157 & -.09 \\
\hline $\mathrm{ZP}$ & & 1 & -.07 & -.035 & -.024 & .022 & .033 & -.115 & -.352 & .11 & $-.58 *$ & -.51 & -.278 & -.176 & -.021 & -.080 & -.383 & .112 & -.156 & $-.441^{*}$ & $-.635 *$ & -.374 & -.219 & -.220 & -.070 & $-.59 * *$ \\
\hline $\mathrm{d}_{0.1}$ & & & 1 & $.97 *$ & $.90 *$ & -.402 & -.127 & -.044 & -.031 & .240 & -.106 & .112 & -.053 & -.055 & -.034 & -.386 & .121 & -.175 & .055 & -.205 & -.26 & -.134 & .128 & -.055 & -.091 & -.17 \\
\hline $\mathrm{d}_{0.5}$ & & & & 1 & $.97 * *$ & $-.47^{*}$ & -.031 & .026 & .030 & .288 & -.048 & .139 & -.016 & -.016 & .033 & -.343 & .147 & -.175 & -.003 & -.202 & -.221 & -.104 & .084 & -.016 & -.080 & -.152 \\
\hline $\mathrm{d}_{0.9}$ & & & & & 1 & $-.460^{*}$ & .042 & .139 & .075 & .312 & .048 & .176 & .094 & .113 & .089 & -.221 & .178 & -.210 & -.056 & -.184 & -.203 & -.079 & .053 & .107 & -.095 & -.155 \\
\hline $\mathrm{pH}$ & & & & & & 1 & $-.57^{* *}$ & -.354 & $-.473^{*}$ & -.391 & -.378 & $-.55^{* *}$ & -.410 & -.322 & -.102 & -.120 & $-.491^{*}$ & -.028 & .202 & -.391 & -.329 & -.032 & .106 & -.362 & -.229 & -.202 \\
\hline OC & & & & & & & 1 & .205 & .378 & -.065 & .265 & .227 & .090 & .009 & -.089 & .241 & .115 & -.151 & -.268 & .238 & .364 & .063 & -.257 & .043 & -.074 & .054 \\
\hline $\mathrm{S}$ & & & & & & & & 1 & $.803^{* *}$ & * $.670^{*}$ & $.712^{* *}$ & ${ }^{* *} .763^{* *}$ & $.755^{* * *}$ & $* .688^{* *}$ & * $.577^{*}$ & $.831^{* *}$ & $.753^{* *}$ & ". $.432^{*}$ & -.348 & $.468^{*}$ & .396 & .324 & -.309 & $.725 * *$ & $.67^{* *}$ & .391 \\
\hline LB & & & & & & & & & 1 & $.555^{*}$ & $.838^{*}$ & $.835^{* *}$ & $.605^{* *}$ & * $.45^{*}$ & $.537^{*}$ & * $.693^{* *}$ & $.820^{* *}$ & .354 & $-.431^{*}$ & $.628^{* *}$ & $.735^{* *}$ & .336 & -.384 & $.521^{*}$ & $.63^{* *}$ & $.60^{* *}$ \\
\hline ТВ & & & & & & & & & & 1 & .372 & $.563^{* *}$ & $.579^{* *}$ & $* .58^{* * *}$ & $.425^{*}$ & .382 & $.647^{* *}$ & * $.531^{*}$ & -.116 & $.453^{*}$ & .205 & .327 & -.057 & $.584^{* *}$ & $.70^{* *}$ & .39 \\
\hline$P$ & & & & & & & & & & & 1 & $.819^{* *}$ & $.766^{* *}$ & * $.659^{* *}$ & .355 & $.613^{* *}$ & $.733^{* *}$ & .295 & -.163 & $.735^{* *}$ & $.794^{* *}$ & ${ }^{*} .462^{*}$ & -.076 & $.711^{* *}$ & $* .546^{* *}$ & $.74^{* *}$ \\
\hline SPS & & & & & & & & & & & & 1 & $.76^{* *}$ & $.608^{* *}$ & .56 & $.565^{* *}$ & $.872 *$ & .349 & -.343 & $.477^{*}$ & $.527^{*}$ & .129 & -.150 & $.679 *$ & $.645^{* *}$ & .48 \\
\hline LPS & & & & & & & & & & & & & 1 & $.93^{* *}$ & $.41^{*}$ & $.617^{* *}$ & $.714^{* *}$ & .354 & -.139 & $.597^{* * *}$ & $.457^{*}$ & .268 & .008 & $.976 * *$ & $.584^{* *}$ & * .50 \\
\hline TPS & & & & & & & & & & & & & & 1 & $.376^{*}$ & $.508^{* *}$ & $.574^{* *}$ & .264 & -.069 & $.535^{* * *}$ & .315 & .250 & .055 & $.989^{* *}$ & $.453^{*}$ & $.418^{*}$ \\
\hline PPS & & & & & & & & & & & & & & & 1 & $.591^{* *}$ & $.605^{* *}$ & .15 & $-.72 * *$ & -.139 & -.097 & -.27 & $-.50^{* *}$ & $.398^{*}$ & .373 & -.010 \\
\hline SPN & & & & & & & & & & & & & & & & 1 & $.60^{* * *}$ & .225 & $-.51^{* *}$ & .294 & .338 & .077 & -.315 & $.56^{* *}$ & $.434^{*}$ & .265 \\
\hline LPN & & & & & & & & & & & & & & & & & 1 & .256 & $-.465^{*}$ & $.464^{*}$ & $.566^{*}$ & .118 & -.296 & $.641^{* *}$ & ${ }^{*} .624^{* *}$ & * $.471^{*}$ \\
\hline TPN & & & & & & & & & & & & & & & & & & 1 & .154 & .288 & .215 & .251 & .071 & .305 & $.915^{* *}$ & * .350 \\
\hline PPN & & & & & & & & & & & & & & & & & & & 1 & .192 & .053 & .309 & $.855^{* * *}$ & -.099 & -.069 & .115 \\
\hline SHA & & & & & & & & & & & & & & & & & & & & 1 & $.885^{* *}$ & $.67^{* * *}$ & .211 & $.57^{* *}$ & $.426^{*}$ & $.87^{* * *}$ \\
\hline LHA & & & & & & & & & & & & & & & & & & & & & 1 & $.711^{* *}$ & .147 & .378 & .445 & $.95^{* *}$ \\
\hline THA & & & & & & & & & & & & & & & & & & & & & & 1 & .238 & .261 & .252 & $.84^{* *}$ \\
\hline PHA & & & & & & & & & & & & & & & & & & & & & & & 1 & .036 & -.066 & .161 \\
\hline EPS-PS & & & & & & & & & & & & & & & & & & & & & & & & 1 & $.51^{* *}$ & $.46^{*}$ \\
\hline EPS-PN & & & & & & & & & & & & & & & & & & & & & & & & & 1 & $.48^{* *}$ \\
\hline EPS-HA & & & & & & & & & & & & & & & & & & & & & & & & & & 1 \\
\hline
\end{tabular}

Correlation is significant at the 0.05 level (2-tailed).

" Correlation is significant at the 0.01 level (2-tailed).

*** Statistical significance ( $p$-value) can reveal the probability of experimental results. If this $p$-value is smaller, the correlation is more significant. 

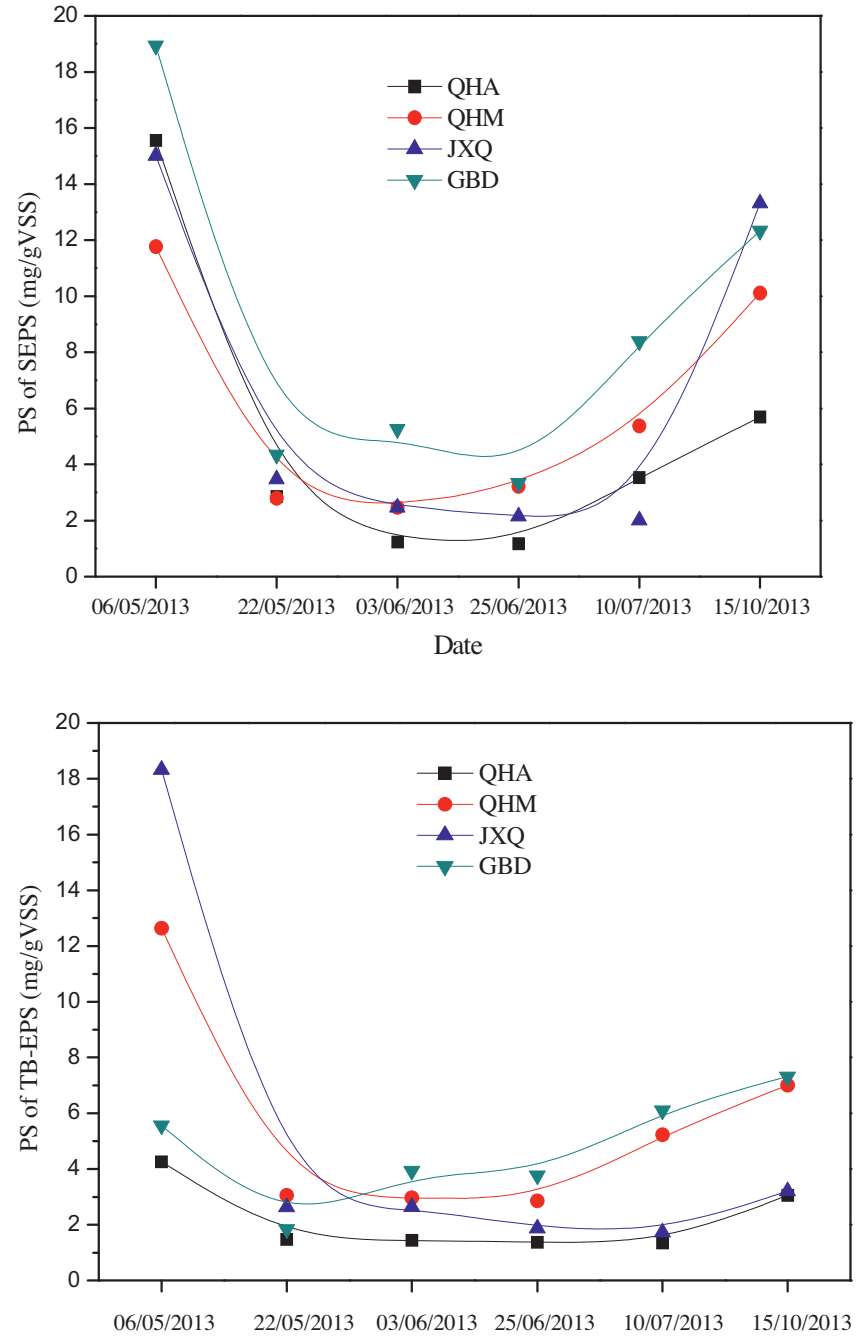

Date
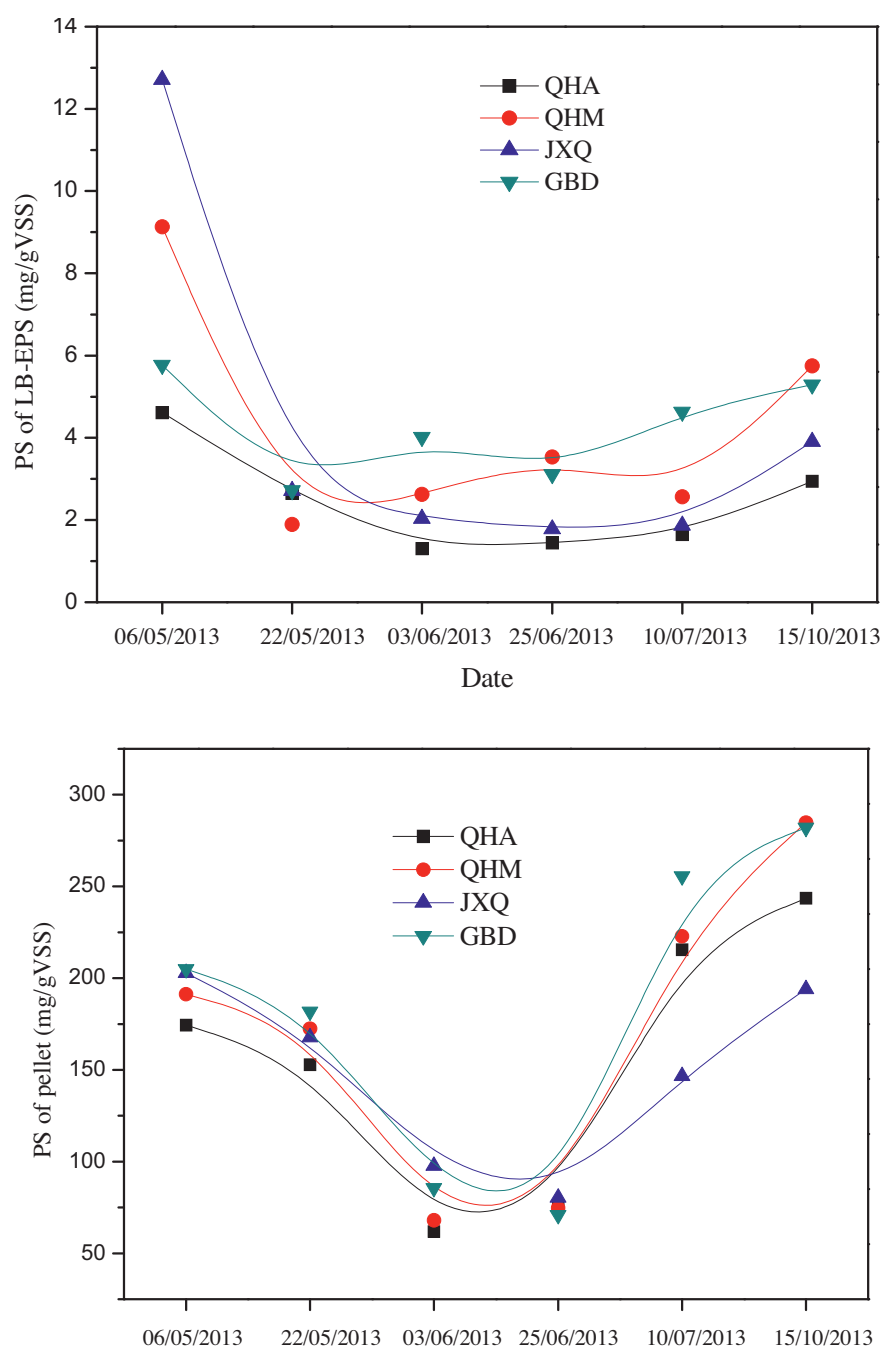

Date

Fig. 5. Polysaccharide concentrations of four EPS fractions in activated sludge from four WWTPs.

\section{Discussion}

\subsection{Effect of operating conditions on EPS properties}

Chemical properties of EPS were closely related to operating conditions and influent quality of WWTPs, such as SRT, HRT, dissolved oxygen, feed strength, carbon/nitrogen $(\mathrm{C} / \mathrm{N})$ ratio. Therefore, it is possible for the operator of WWTPs to regulate the operating parameters to reduce the production of soluble EPS and provide a sludge with good dewaterability. Generally, the exogenous carbon source (methanol and sodium acetate) has to be provided as an electron donor for efficient nitrate removal by denitrification in the bioreactors [18]. Ye et al. observed that higher $\mathrm{COD} / \mathrm{N}$ ratios resulted in increase of the content of PS and decrease of protein content in EPS [19]. As stated by Barker and Stuckey, a certain optimum range of HRT and SRT exists in which it is possible to obtain minimum values of SEPS [20]. When soluble EPS production was plotted against SRT and HRT, it appeared to decrease to a minimum and then increase again, indicating the existence of an optimal SRT and HRT for minimizing the SEPS production. Furthermore, anaerobic storage of activated sludge, which often takes place at wastewater treatment plants before dewatering, causes a breakage of sludge and release of soluble EPS, consequently a deterioration of the sludge dewatering property $[21,22]$.
Low temperature periods might cause a change in both the raw wastewater composition and in the physicochemical properties of the activated sludge, affecting subsequent processes. The microbial activity was always inhibited under low temperatures, leading to a slower biodegradation of the wastewater in the mixed liquor compared to high temperatures [23]. This observation could be confirmed by increased concentration of soluble EPS in this study. In addition, EPS distribution and composition in sludge floc was primarily related to operating temperature. The content of total extractable biopolymer was decreased while the protein in pellet was increased in summer, revealing that the protein transfer from EPS fractions to pellet at higher temperatures. Since the binding strength of EPS on microbial cells decided the extractability of EPS, the floc density in summer was higher than that in winter. Again, it is interesting to note that increase in protein concentration in whole sludge floc was observed in summer. As mentioned earlier, the protein-like substances were actually exoenzymes secreted by bacteria; hence increase in content of proteins indicated higher microbial activity. This is consistent with the report of Wilén et al. [24], who suggested that enhancement of floc strength could be obtained when the aerobic microbial activity was improved by regulating operating conditions. Jiang et al. reported that low temprature caused deterioration in bioflocculation properties and deflocculation of activated sludge, subsequently resulting in 


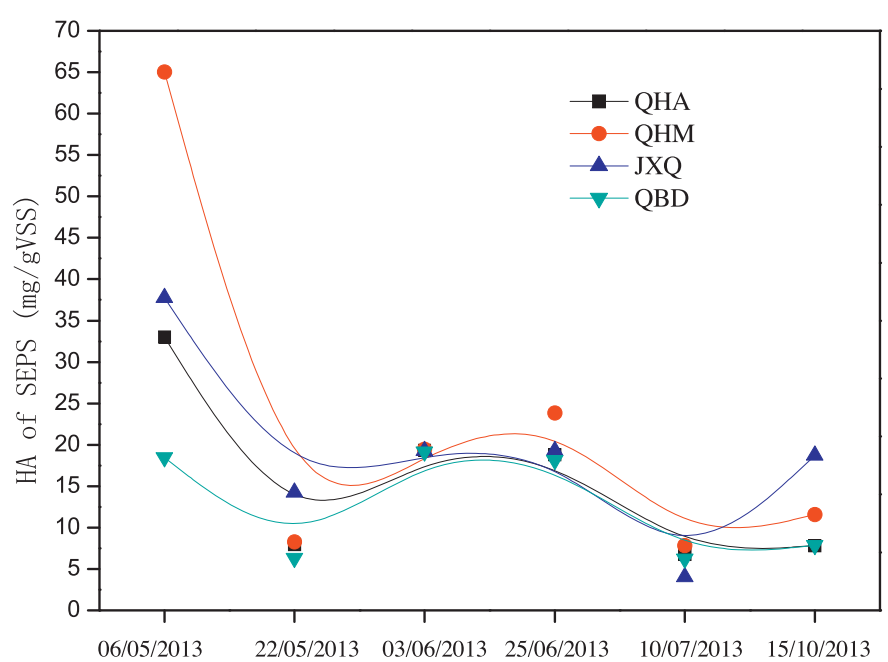

Date

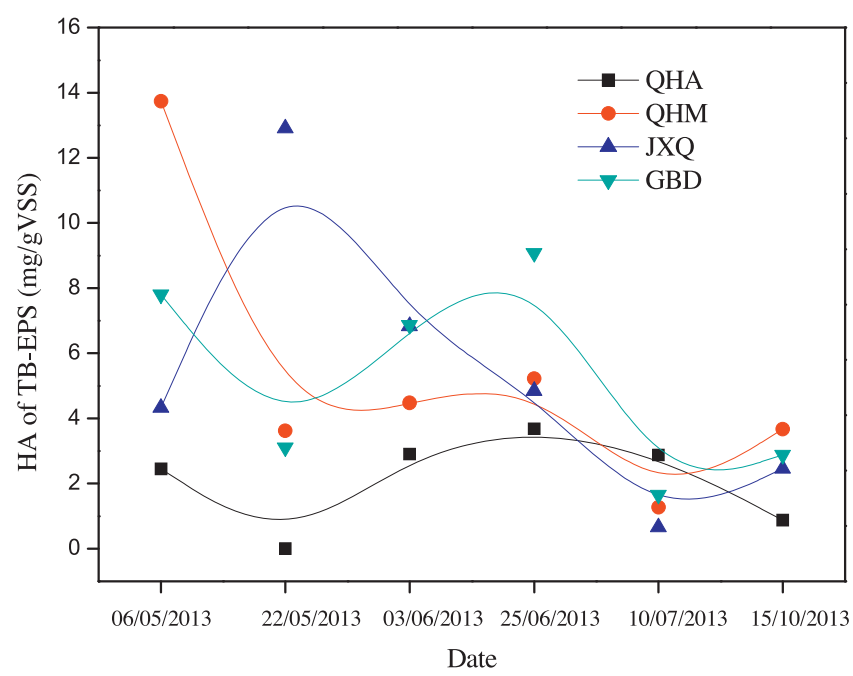

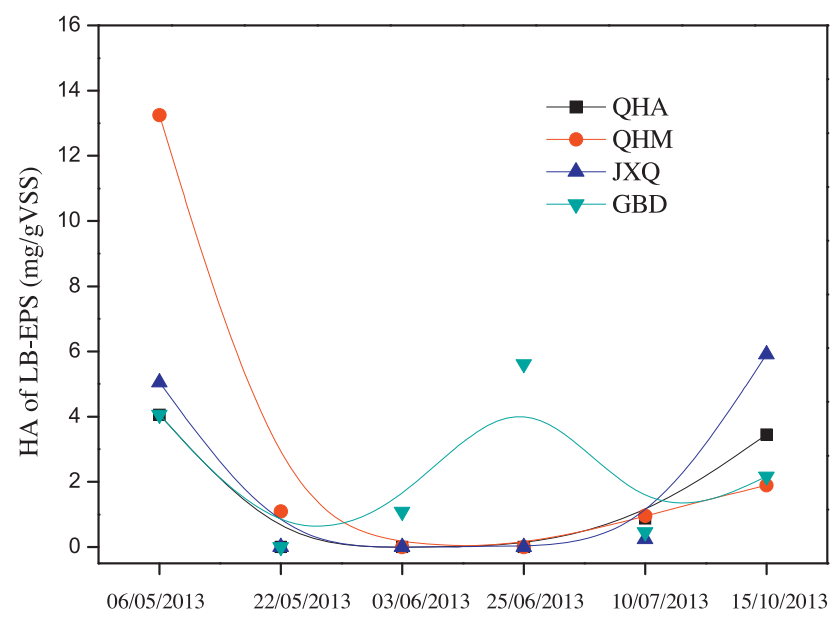

Date

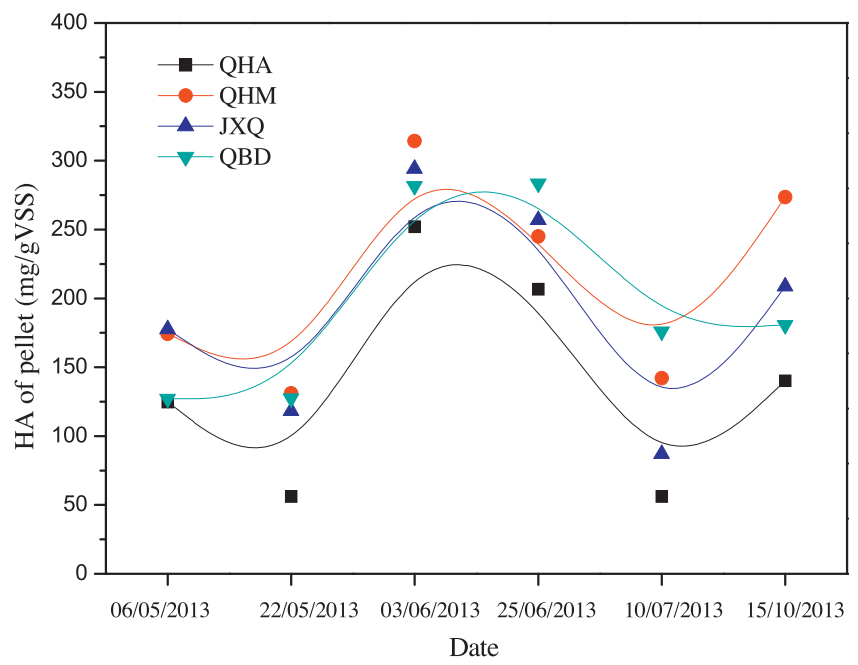

Fig. 6. Humic acid concentrations of four EPS fractions in activated sludge from various WWTPs.

reduction of floc size and release of EPS [25]. However, no obvious variation in particle size was detected for each WWTP investigated.

\subsection{Effect of floc properties on sludge settling and dewatering performance}

\subsubsection{Sludge dewaterability}

It was reported by many studies that sludge dewatering behavior was primarily influenced by distribution and composition of biopolymers rather than sludge floc as a whole. It was noted that EPS of activated sludge particles are not uniform and are likely to have a dynamic double-layered structure of loosely bound EPS (LBEPS) diffused from the tightly bound EPS (TB-EPS) [6]. According to the binding strength of EPS to cells, Li and Yang used a two-step heat extraction method to fractionate the EPS into LB-EPS and TB-EPS [6]. The sludge dewatering performance was more strongly negatively correlated with the LB-EPS content rather than that of TB-EPS or total EPS. Additionally, they also found that the sludge flocculating behavior, settleability, compressibility and dewaterability correlated well with LB-EPS content rather than TB-EPS content under the non-steady-state operation [26]. Recently, Yu et al. fractionated sludge floc into five layers (supernatant, slime, LB-EPS, TB EPS and pellet) with combined ultrasound and centrifugation treatment. A strong correlation was found between the parameters for sludge dewatering characteristics and protein concentration in the supernatant, slime, and LB-EPS, while no correlation showed between organic composition in the pellet and the sludge flocs as a whole [7]. From this study, there was strong correlation between sludge dewateability and the content of total SEPS and PN in SEPS. Although the SEPS accounted for less than $5 \%$ of total extractable biopolymer, they play more important roles in sludge dewatering process than other fractions of sludge floc. Again, since EPS compression was the major mechanism of sludge conditioning with traditional inorganic coagulants [10], indicating that extractable EPS content was one of the most important factors affecting the optimal dosage of chemical conditioner. This observation can be confirmed by the fact that the dosage of chemical conditioners for most of WWTPs was significantly increased in winter due to high EPS production and low temperature. Zhang et al. suggested that addition of inorganic polymer flocculants (IPFs) was very effective to remove the sticky soluble EPS from sludge bulk and improve the sludge filterability and dewaterability [27].

\subsubsection{Sludge settling property}

Many studies demonstrated that the sludge settleability or compression was associated with the EPS properties in sludge system. A larger amount of total EPS was detrimental to bioflocculation and resulted in poorer settleability or compression. Li and Yang 
demonstrated that the sludge settleability was mainly governed by the concentration of LB-EPS, excessive LB-EPS could weaken the floc structure and result in poor bioflocculation ability and sludge-water separation properties [6]. On the contrary, SVI was found to be simply related to the floc size distribution and organic content (VSS/TSS) of activated sludge in this study. In general, no significant change in floc size of sludge was observed for each WWTP with operating time. The floc size is a simple reflection of bioflocculation ability; the larger sludge floc was always related to better bioflocculation property. Obviously, the sludge from GBD WWTP exhibited better settling performance compared to that of other WWTPs, meanwhile the floc size of GBD sludge was also the largest. It could be attributed to the addition of aluminum sulfate for improving phosphate removal in GBD WWTP. Cations, especially divalent and trivalent, can bridge these negatively charged sites on EPS, binding them to microbial surfaces and to other biopolymers, therefore they played very crucial roles in bioflocculation [28]. It should be pointed out that although the QHA and QHM WWTPs received the same influent, the average sludge floc size of QHA was larger than that of QHM. The difference in sludge floc size between these two processes might be due to the strength of mechanical shear force exerted by aeration. For MBR process, the high aeration intensity was generally required to prevent deposition of colloidal particles on the membrane surface and maintain the stability of membrane flux. However, the activated sludge flocs readily break into smaller units as they grow under the high aeration rate. In addition, high organic content in solid was detrimental to sludge settling process. It was generally accepted that the floc structure appears to be looser and more difficult to settle with increase of organic fraction in sludge solid.

\section{Conclusion}

In this study, dynamic variation of physicochemical properties, especially EPS of sludge floc was investigated in detail in order to find out the key factors affecting sludge dewatering and settling performance. The results indicated that EPS content was much higher at low temperature, and protein-like substances were very likely to transfer from EPS fractions to pellet at higher temperatures. The sludge dewaterability and settleability were governed by different factors. The former was primarily decided by protein-like substances in soluble EPS, while the latter was mainly dependent on floc size distribution and VSS/TSS ratio.

\section{Acknowledgments}

This study was financially supported by the State Water Project for Integrated Water Supply Sludge Quality and Depth of Dewatering Technology (2012ZX07408001-05) and the National Natural Science Foundation of China (41201498).

\section{References}

[1] K. Thapa, Y. Qi, A. Hoadley, Interaction of polyelectrolyte with digested sewage sludge and lignite in sludge dewatering, Colloids Surf. A: Physicochem. Eng. Aspects 334 (2009) 66-73.

[2] L.F. Zhai, M. Sun, W. Song, G. Wang, An integrated approach to optimize the conditioning chemicals for enhanced sludge conditioning in a pilot-scale sludge dewatering process, Bioresour. Technol. 121 (2012) 161-168.

[3] Y. Wang, Y. Dong, J. Feng, Scaling behaviors of unconditioned and conditioned water treatment residuals (WTRs) based on rheological and microscopic characterization, Colloids Surf. A: Physicochem. Eng. Aspects 402 (2012) 152-158.
[4] Y. Liu, H.H. Fang, Influences of extracellular polymeric substances (EPS) on flocculation, settling, and dewatering of activated sludge, Crit. Rev. Environ. Sci. Technol. 33 (2003) 237-273.

[5] C.S. Laspidou, B.E. Rittmann, A unified theory for extracellular polymeric substances, soluble microbial products, and active and inert biomass, Water Res. 36 (2002) 2711-2720.

[6] X. Li, S. Yang, Influence of loosely bound extracellular polymeric substances (EPS) on the flocculation, sedimentation and dewaterability of activated sludge, Water Res. 41 (2007) 1022-1030.

[7] G.H. Yu, P.J. He, L.-M. Shao, P.-P. He, Stratification structure of sludge flocs with implications to dewaterability, Environ. Sci. Technol. 42 (2008) 7944-7949.

[8] D.S. Wang, L.N. Xing, J.K. Xie, C.W.K. Chow, Z.Z. Xu, Y.M. Zhao, M. Drikas, Application of advanced characterization techniques to assess DOM treatability of micro-polluted and un-polluted drinking source waters in China, Chemosphere 81 (2010) 39-45

[9] R. Govoreanu, Activated Sludge Flocculation Dynamics: On-line Measurement Methodology and Modelling/Door Ruxandra Govoreanu, Ghent University, 2004.

[10] M. Niu, W. Zhang, D. Wang, Y. Chen, R. Chen, Correlation of physicochemical properties and sludge dewaterability under chemical conditioning using inorganic coagulants, Bioresour. Technol. 144 (2013) 337-343.

[11] B.M. Wilén, D. Lumley, A. Mattsson, T. Mino, Relationship between floc composition and flocculation and settling properties studied at a full scale activated sludge plant, Water Res. 42 (2008) 4404-4418.

[12] S. Lyko, T. Wintgens, D. Al-Halbouni, S. Baumgarten, D. Tacke, K. Drensla, A. Janot, W. Dott, J. Pinnekamp, T. Melin, Long-term monitoring of a full-scale municipal membrane bioreactor - characterisation of foulants and operational performance, J. Membr. Sci. 317 (2008) 78-87.

[13] P. Lembre, C. Lorentz, P. Di Martino, Exopolysaccharides of the biofilm Matrix A Complex Biophysical World, The Complex World of Polysaccharides, InTech, 2012, pp. 371-392

[14] B. Wilen, D. Lumley, A. Mattsson, T. Mino, Rain events and their effect on effluent quality studied at a full scale activated sludge treatment plant, Water Sci. Technol. 54 (2006) 201-208.

[15] L. Xi, N. Lv, H. Zhang, B. Sun, Analysis of formation and degradation mechanism of soluble microbial product and its effect on membrane filterability for membrane bioreactor, CIESC J. 64 (2013) 3003-3008 (in Chinese).

[16] S. Comte, G. Guibaud, M. Baudu, Effect of extraction method on EPS from activated sludge: an HPSEC investigation, J. Hazard. Mater. 140 (2007) 129137.

[17] A. Ramesh, D.-J. Lee, S. Hong, Soluble microbial products (SMP) and soluble extracellular polymeric substances (EPS) from wastewater sludge, Appl. Microbiol. Biotechnol. 73 (2006) 219-225.

[18] C. Srinandan, G. D’souza, N. Srivastava, B.B. Nayak, A.S. Nerurkar, Carbon sources influence the nitrate removal activity, community structure and biofilm architecture, Bioresour. Technol. 117 (2012) 292-299.

[19] F. Ye, Y. Ye, Y. Li, Effect of C/N ratio on extracellular polymeric substances (EPS) and physicochemical properties of activated sludge flocs, J. Hazard. Mater. 188 (2011) 37-43.

[20] D.J. Barker, D.C. Stuckey, A review of soluble microbial products (SMP) in wastewater treatment systems, Water Res. 33 (1999) 3063-3082.

[21] Z. Lei, X. Luo, Z. Zhang, N. Sugiura, Effects of variations of extracellular polymeric substances and soluble microbial products on activated sludge properties during anaerobic storage, Environ. Technol. 28 (2007) 529-544.

[22] P.H. Nielsen, B. Frølund, K. Keiding, Changes in the composition of extracellular polymeric substances in activated sludge during anaerobic storage, Appl. Microbiol. Biotechnol. 44 (1996) 823-830.

[23] P. Krzeminski, A. Iglesias-Obelleiro, G. Madebo, J. Garrido, J. van der Graaf, J van Lier, Impact of temperature on raw wastewater composition and activated sludge filterability in full-scale MBR systems for municipal sewage treatment, J. Membr. Sci. 423 (2012) 348-361.

[24] B.M. Wilén, J. Lund Nielsen, K. Keiding, P.H. Nielsen, Influence of microbial activity on the stability of activated sludge flocs, Colloid Surf. B: Biointerfaces 18 (2000) 145-156.

[25] T.Jiang, M.D. Kennedy, B.F. Guinzbourg, Optimising the operation of a MBR pilot plant by quantitative analysis of the membrane fouling mechanism, Water Sci. Technol. 21 (2005) 19-25.

[26] S.F. Yang, X.Y. Li, Influences of extracellular polymeric substances (EPS) on the characteristics of activated sludge under non-steady-state conditions, Process Biochem. 44 (2009) 91-96.

[27] W. Zhang, P. Xiao, Y. Liu, S. Xu, F. Xiao, D. Wang, C.W. Chow, Understanding the impact of chemical conditioning with inorganic polymer flocculants on soluble extracellular polymeric substances in relation to the sludge dewaterability, Sep. Purif. Technol. 132 (2014) 430-437.

[28] H. Li, Y. Wen, A. Cao, J. Huang, Q. Zhou, P. Somasundaran, The influence of additives $\left(\mathrm{Ca}^{2+}, \mathrm{Al}^{3+}\right.$, and $\left.\mathrm{Fe}^{3+}\right)$ on the interaction energy and loosely bound extracellular polymeric substances (EPS) of activated sludge and their flocculation mechanisms, Bioresour. Technol. 114 (2012) 188-194. 